\title{
A Study on Significance of System Dynamics Approach in Understanding Adoption of Information Technology in Building Construction Projects
}

\author{
Vinay Mathews, Koshy Varghese, and Ashwin Mahalingam \\ Building Technology and Construction Management Division, Civil Engineering Department, Indian Institute of \\ Technology Madras, India \\ E-mail: vinaymathews30@gmail.com, koshy@iitm.ac.in, mash@iitm.ac.in
}

\begin{abstract}
-
Today several activities of a construction project can be supported with information technology tools. However, there have been many cases of technology adoption failure. Lack of understanding about the process of technology adoption is often pointed out as the reason. This paper is based on a study to explore BIM technology adoption process and attempt to model and evaluate the process using system dynamics. The paper has its base on literature survey and five month field studies of three construction projects where BIM was being introduced. Insights from literature survey and case studies were used to develop a core system dynamics model of technology adoption. To this core, project and technology specific data was added to develop a preliminary system dynamics model. The research indicates that system dynamics is a promising approach in improving our understanding of technology adoption in construction projects.
\end{abstract}

Keywords -

System dynamics; Construction projects; Information technology; Adoption

\section{Introduction}

Usage of Building Information Modelling (BIM), Enterprise Resource Planning (ERP) and other information technology tools are rapidly growing in construction industry. Suitability and effectiveness of such tools in a given construction project are uncertain.

Technology developers can guide construction companies in understanding the advantages of using technology. But the complexities that emerge in the learning phase of technology adoption are still unclear.

Acceptance and adoption of information technology has been a popular research issue [1]. Over the past two decades, researchers have developed many frameworks to help decide on the suitability and acceptability of technology. Technology Acceptance Models (TAM) are popular in predicting and explaining technology use [2, $3]$. But they concentrate on technology adoption by individual users. TAM models are not suitable to study adoption of collaborative technology in construction projects, where the use by an individual user is not significant.

Recently, there have been studies that looked into organisational aspects of technology adoption in construction industry [4-6]. But they are yet to find place in any of the IT adoption models.

Many studies were taken up to understand technology adoption specific to construction industry. Most of these studies focus on identifying new factors that plays a crucial role in technology adoption. While these exploratory studies are relevant in identifying influencing factors, there is no guidance suggested to a project manager on which factors to focus on while selecting and adopting a technology [7]. Further, correlation between these factors is not known and the alignment of factors required for successful technology adoption is also not tested.

System Dynamics (SD) is an approach used to understand behaviour of complex systems over a period of time [8]. The use of SD to model construction projects is not new [9]. SD has also been used in fields like agriculture to understand technology adoption [10]. In this paper, a preliminary evaluation of system dynamics to model technology adoption in construction projects is explored.

The paper is a part of a larger research that looks at improving technology adoption in construction projects. The first author spent 5 months as an observer on three construction projects that were initiating the use of BIM. Several observations of the BIM adoption process were made during this field study phase. This paper attempts to structure these observations as well as aspects reported in literature to understand the process of technology adoption and represent this using SD.

The next section of this paper presents the findings 
from reviewed literature to understand the current state of knowledge on technology adoption. The details of three field studies conducted and the observations made are presented in Section 3. The insights from case studies have been detailed in Section 4. Section 5 discusses the development of the system dynamics model based on the insights on technology adoption from literature and field studies. Section 6 discusses the utility of the system dynamics model in understanding technology adoption process.

\section{Literature Review}

Among the many studies on information technology adoption, Technology Acceptance Models TAM, TAM2, UTUAT are among the most popular.

Unified Theory of User Acceptance and Use of Technology (UTUAT) [11] is a highly cited work on technology adoption. The paper summarises eight user acceptance models and also proposes a unified theory bringing together the best features from all those.

Eight models that are unified in the paper are Theory of Reasoned Action (TRA), Technology Acceptance Model (TAM), Motivational Model (MM), Theory of Planned Behaviour (TPB), Combined TAM and TPB (C-TAM-TPB), Model of PC Utilisation [12], Innovation Diffusion Theory (IDT) and Social Cognitive Theory (SCT).

TRA, proposed by Fishbein and Ajzen [13] suggests that the behaviour of an individual is affected by one's own attitude and subjective norm. Subjective norm is an individual's perception of what behaviour is expected of him from others.

TAM, which has its basis on TRA, included constructs like usefulness and usability of a technology in predicting the chances for successful adoption of technology [14]. TAM initially did not take the concept of social norm from TRA. However TAM2 included subjective norm to it after studies proved its importance.

MM describes intrinsic and extrinsic motivation for behaviour. Intrinsic motivation refers to the motivation that drives a particular behaviour to enjoy the behaviour itself. External motivation refers to the behaviour which is driven by the end result. It also tries to explain the interrelationship that intrinsic and extrinsic motivation has [15]. Social Cognitive Theory (SCT) by Albert Bandura looked in to learning from observation and action. The concept of self-efficacy was also brought out in SCT. Self-efficacy is the self-belief of a person in completing a given task [16]. TPB is an extension of TRA, with the idea of self-efficacy borrowed from SCT. C-TAM-TPB combines the best of TAM and TPB [11]. IDT describes the process of diffusion of an innovation in a group [17]. MPCU tries to understand the factors that affect the use of personal computers (PC). Social norm and expected consequences of using PC were found to be the major factors that influence PC usage.

Venkatesh et al's [11] summary of all acceptance models could be given a pictorial representation as shown in Figure 1.

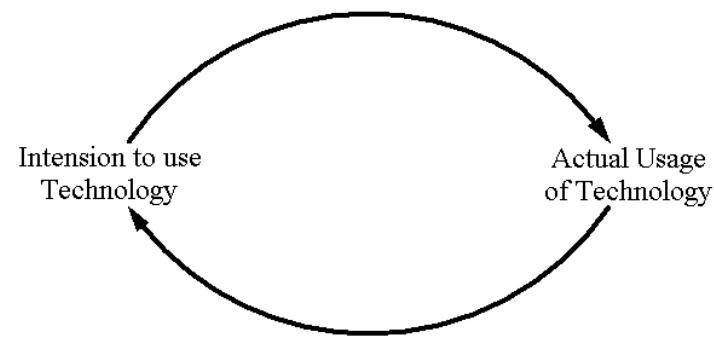

Figure 1. Underlying concept of all acceptance models

TAM models, with their origins in psychology, concentrate on adoption of technology by individuals. While it is good to have an understanding of technology adoption by each user, system level understanding of technology adoption would enable decision making on selection and improvement of technology adoption. Details on technology adoption by individual users in a time bound project setting may not be of much use.

Technology developers embed a process to the technology. The closeness of this process to organisation's work practices has a significant influence on the ease of implementation. Many of the research works agree on the need to select technology that is closely aligned with the existing work practices $[18,19]$

If both organisation and technology were to be rigid, selection of proper technology would have been the only area that researchers could look into. Building on the existing literature of structuration theory [20], many other theories have come out which endorses the fact that technology and organisational structures are not rigid and can actively engage in restructuring one another $[21,22]$. This brings out the importance of activities surrounding technology development and technology implementation in determining the acceptability of technology. Whyte [6] elaborates on hybrid practices that emerge when digital technology is introduced in to an institutionalised organisation. Dossick and Neff [5] discuss the importance of messy talk for effective communication and problem solving in projects involving multiple teams. They define messy talk as "conversations neither about topics on meeting agendas, nor on specified problems or specific queries for expertise". Technology can create trading zones, which increase collaboration within various teams and thereby becoming an integral part of the organisation [4, 23]. Many of these recent findings have not yet found place in any of the frameworks for successful technology adoption. 
There have been exploratory studies to find both technical and nontechnical factors that affect technology adoption in construction industry. Sargent, K et al extended UTUAT by adding the element Top Management Support [24]. Peansupap et al conducted an exploratory study to come up with factors that influence adoption of IT in Australian construction organisations [25]. These factors were 11 in number, classified to four categories - Individual, Environment, Management, and Technology. Nikas, A et al [26] describes the importance of considering antecedents of technology adoption separately from drivers of technology adoption.

In the above studies, the authors have either stated the explored factors as independently or positioned them as extensions of any of the existing technology acceptance models. While it is essential to have exploratory studies in the initial stages, it is equally important to have a framework that can comprehensively accommodate their results. A framework is essential to develop models that can be used to make sense of the entire system. Currently, there are no frameworks that are specifically developed to understand technology adoption in projects.

The data from field study were used to understand the dynamics of technology adoption in a construction project. This understanding was later used to develop a framework for technology adoption model suitable to construction industry.

\section{Field Study}

Field studies were conducted in three construction sites located in three different cities in India over a period of 5 months. The purpose of these field studies was to observe the technology adoption in these construction sites.

The first author spent five months in these three sites The inputs for these studies mainly came from interviews, observations in construction sites, attending weekly meeting on BIM and MEP coordination meetings.

The client for all the three projects was a leading IT company in India. All projects were executed on a fast track basis, meaning - construction process was concurrent with design process. In each of these sites, a Project Management Consultancy (PMC) was appointed for overall planning and coordination of the works. Separate organizations for architecture, structural design, MEP design were a part of the project team. A main contractor (MC) did the civil works. Specialised MEP sub-contractors were nominated by the client, but reported to main contractor.

BIM Agency (BIMA) was appointed in all the three cases. Their responsibility included developing 3D model from design drawings, clash detection and clash resolution of MEP drawings. They also had to prepare weekly status report of the construction activities based on inputs from construction site. In one of the sites, BIMA reported directly to the main contractor, whereas in other cases, BIMA reported to the owner.

Table 1 gives a brief description of the similarities of the cases studied.

Table 1. Similarities in cases studied

\begin{tabular}{cc}
\hline Item & Description \\
\hline Type of Building & IT Building \\
Owner & Leading Indian IT \\
& Company \\
Project Delivery Method & Design Bid Build \\
Time of Study & Construction Phase \\
Built up area & Approx. 2 M SQF \\
Location & Across India \\
BIM modules used & BIM Clash Detection, \\
& BIM Status Report \\
\hline
\end{tabular}

\subsection{Clash Detection Using BIM}

In all three cases, manual clash detection of MEP services was to be replaced with BIM based clash detection. Although not in a deliberate fashion, concepts from Socio-Technical Systems Design(STSD) literature [27] were utilised for study project design in all the three cases. STSD highlights the importance of considering people, technology and context in a holistic manner. In accordance with STSD, technology change was implemented with associated changes in people and organisational structure.

MEP designer continued to make designs in CAD and main contractor used $\mathrm{CAD}$ in execution of construction work. BIMA took drawings from MEP consultant, architect and structural consultant to develop BIM model from the 2D drawings. After clash detection, clashes were resolved in discussion with MEP consultant, architect, structural consultant, main contractor and sub-contractors. The proposed workflow seemed appropriate in the beginning. With least possible interference made with institutionalised Indian construction practices, BIM was to be used for clash detection and resolution. But, things did not happen as expected. Each of the three cases had different responses.

\subsubsection{Case 1}

BIMA had to make 20 revisions of first floor BIM model before releasing good for construction drawings. 
The unexpected BIM revisions delayed the start of execution of first floor MEP works by 15 days. The reason for one such revision was that BIMA had left out $\mathrm{AC}$ duct insulation in the BIM model. The 2D drawings that were given by main contractor to BIMA did not have AC duct insulation. BIMA, whose job is to develop the BIM model of given 2D drawings, did not consider it necessary to model elements that are not present in the 2D drawings. Main contractor did not include insulation of duct in 2D drawings as that was the convention that the industry has been following. The main contractor believed that it was lack of technical knowledge of BIMA which lead to this problem. From an outsider perspective, the presence of a proper information sharing protocol could have avoided this.

The PMC on site insisted that MEP works could start only after BIM clash free drawings were released. PMC head said that he was under tremendous pressure to release drawings. None of the MEP sub contractors wanted their engineers and workers to stay idle in site, waiting for release of drawings. After the release of first floor drawings, decision was made to discontinue mandating BIM generated clash free model as a necessary step before execution.

\subsubsection{Case 2}

BIM clash detection and resolution began much earlier in this site. BIMA representative on site coordinated many clash resolution meetings on site. Members from design offices and BIMA participated in many of these meetings using teleconferencing and screen sharing. But clash resolution process was not completed as estimated. In one case, BIMA prepared the model with old versions of a few drawings. It was during clash resolution meetings that other parties pointed out this discrepancy to BIMA. PMC, who was in charge of forwarding design drawings to BIMA, blamed BIMA for not incorporating the changes. BIMA denied receiving these revised drawings from PMC. Despite exceeding the initial time estimates, clash free model of first floor drawing was released without causing any delay in MEP work execution. Having taken up the entire buffer for first floor, it was anticipated that BIM clash free drawing of subsequent floors would be delayed. So, it was decided that BIM clash free drawing will be used only if it does not delay start of execution of MEP works.

\subsubsection{Case 3}

Despite many difficulties, BIM clash detection continued to be a prerequisite before execution. The quality of the clash free model was not good enough. An onsite MEP engineer said," BIM doesn't give clash free model. It is in site that all the clashes are resolved. "Another MEP engineer said, "The BIM coordinated drawing when compared to the old style of manual coordination does not bring any change. Not better not worse."

There was a clear disconnect between PMC and MC in this site. Given below is a snippet from a site meeting called by PMC to communicate the necessity to have as built drawing.

PMC: "Whenever we say something you say against it. Every time you are talking negative....... We will have to cut your payment"

MC: "Every time you are cutting our payment. Show in contract document where it is written to submit as built drawings."

PMC did not react to what was happening in site. PMC continued to insist the need to have BIM clash free drawing.

\subsection{Status Report Using BIM}

In all the three cases studied, weekly project status report was prepared by BIMA from beginning of construction phase. BIMA used baseline schedule prepared by Project Management Consultancy and the updates from contractors for preparing the graphical status report. The report was used by client team to monitor the delays closely. The site team, actively engaged in construction process, did not need a BIM report to understand progress. Sitting in his site office, a PM gave the following remark on the usefulness of status report using BIM, "I move these curtains and I know the status of this bloody building".

This monitoring was not effective because the level of detail of the 4D BIM model was inappropriate for weekly monitoring in all of the sites. In original base line model, concreting of all 100 columns in a floor was represented as a single activity. The BIM status report could only show the progress of work for the entire set of 100 in a single state. So, even when a single column of the 100 was not completed, all 100 shown to be in progress. This miscommunication of actual status resulted in frequent queries on slow progress by management. Hence the BIM report required frequent explanation for the differences in BIM model and the actual progress of work. To resolve this miscommunication it was decided that baseline schedule would be expanded to include individual column-wise details. This ensured that BIM status report was up-todate with actual construction to the detail of a single column. PMC, MC and BIMA had to do extra work to incorporate these changes. Project schedule such minute 
details was new to all the project participants.

Although the site faced initial problems with the BIM report, there was no indecisiveness on the need to have BIM status report in any of the three construction sites. After appropriate level of detail was modelled, accurate BIM status report was generated in all the three sites. The client team, which was away from the site, could better understand the site progress.

\section{Discussion on field study}

This section tries to understand the dynamics involved in IT adoption in the three cases. The dynamics so identified has been used in Section 5 for developing a system dynamics framework of technology adoption in construction industry.

Two underlying features of technology adoption process in the cases: 1. constant conflict between existing and new work flows. 2. variation of factors across adoption time

\subsection{Constant conflict between existing and new work flows}

There are several uncertainties in the learning phase of technology adoption. Figure 2 is a pictorial representation of the resulting adoption trajectories. Trajectory 1 represents case 3 in clash detection section. Here, the effort to use a technology continues, without the desired outcome. Trajectory 2 represents the successful status report generation module of BIM in all the three cases. In this trajectory, all the complexities that came across were overcome. Case 1 and case 2 of clash detection module are represented by trajectory 3 .

The figure reveals one feature that is often left out in most of the technology acceptance literature. There is always a tendency for a project to discontinue the usage of a new technology and go back to old technology. Institutional theory can be used to explain the bearing a project has from previous projects and experience of its participants $[28,29]$. Though each project is unique and can be designed individually, there is always a power struggle between the comforts of the established norms and benefits of new design tools.

The observation matches with 'Relative Advantage' concept by Rogers [17] to an extent. Relative Advantage is the perceived advantage of an innovation when compared to the conventional one. The main difference of 'Relative Advantage' with the observation here is the dynamicity associated.

\subsection{Variation of factors across time:}

In the three cases listed in Section 3, BIM was initially used for clash detection. Among the three, two of the projects discontinued its usage later. This discontinuation indicates that there have been some changes in factors that affect technology adoption as project progressed.

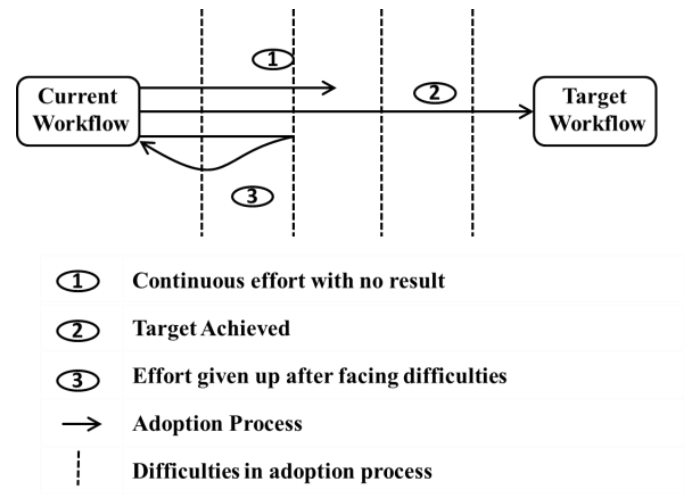

Figure 2: Three trajectories of technology adoption

The Project Manager's and field engineer's commitment to use BIM is likely to diminish with time if the results are not useful for their core function. Another aspect which could change with time is the standards and protocols of information exchange.

\section{System Dynamics Model}

System Dynamics is a modelling and simulation technique to understand the behaviour of complex systems over the period of study. System Dynamics does not look into details of individual participant, but looks things at a system level. This makes SD suitable for developing a framework for technology adoption in construction industry.

In this section, the details of formulating a system dynamics model of adoption of BIM adoption have been discussed. The development consisted of two phases:

1. Build a framework for a model that could be used irrespective of the project and technology under consideration

2. Use project specific data to complete the model

Two features formed the core of the framework of system dynamics model. One based on literature and other on the case study:

a. A cyclic relation between intention to use a technology and actual usage at project level. (From Figure 1 in Literature Review Section) 
b. Constant power struggle between new workflow and the existing work flow (from case study)

In figure 3, 'Actual new workflow rate' and 'Actual conventional workflow rate' have been used to represent the existence of two conflicting workflows. Also, variables 'Actual new workflow rate' and 'Intention to use new workflow' have been cyclically connected by variables 'Total work done in new workflow' and 'Relative Advantage'.

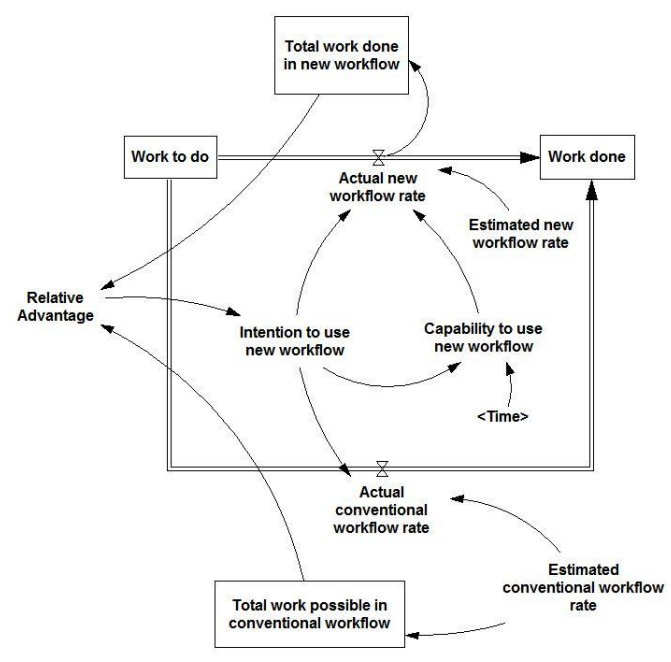

Figure 3. Proposed framework for SD model on technology adoption

The framework is an abstract SD model that could be reused for any technology adoption process in construction industry. It should be possible to enter project and technology specific details to the abstract model.

A system dynamics model was developed from this abstract model to validate the extensibility of the abstract model. As development of system dynamics model is more at the discretion of modeller, a model developed at a particular site by the researcher could be biased in favouring the universality of the abstract model. To overcome this, the model was developed based on an international survey by Won et al [7] which looked into critical success factors(CSF) for BIM adoption. Twenty four CSF emerged from the study, which involved 52 expert responses from 4 continents. The study included weight of each of these CSF on a scale from 1 to 7 . It was observed that the all the CSF were contributing either to 'Intention to use new workflow' or 'capability to use new workflow' or both. None of the CSF had to be left out from the model. The classification of these factors is given in Table 2 .

Together with values from the study and a few assumed values for variables like 'estimated new workflow rate' and ' estimated conventional workflow rate', hypothetical SD models were developed for adoption of BIM clash detection and status report.

Table 2. Influencing Factors [7]

\section{Factor}

Willingness to share information

Master BIM Manager

Effective Collaboration

Organisational Structure

Continuous Investment

Senior Management Leadership

Information Sharing Protocol

BIM Training Program

Technical Support for Interoperability

Standardised Work Procedures

PM Interest

Request from client

Project Complexity

Field Engineer's interest

Architect Firm's use

Result Demonstrability

Expected ROI

Company's business strategy

Usefulness of technology in project

BIM technology capability

Known successful cases of BIM

Software Interoperability

Institutionalisation of BIM application

Modelling ease

* IU - Intention to Use Technology

$\wedge \mathbf{C U}$-Capability to Use technology
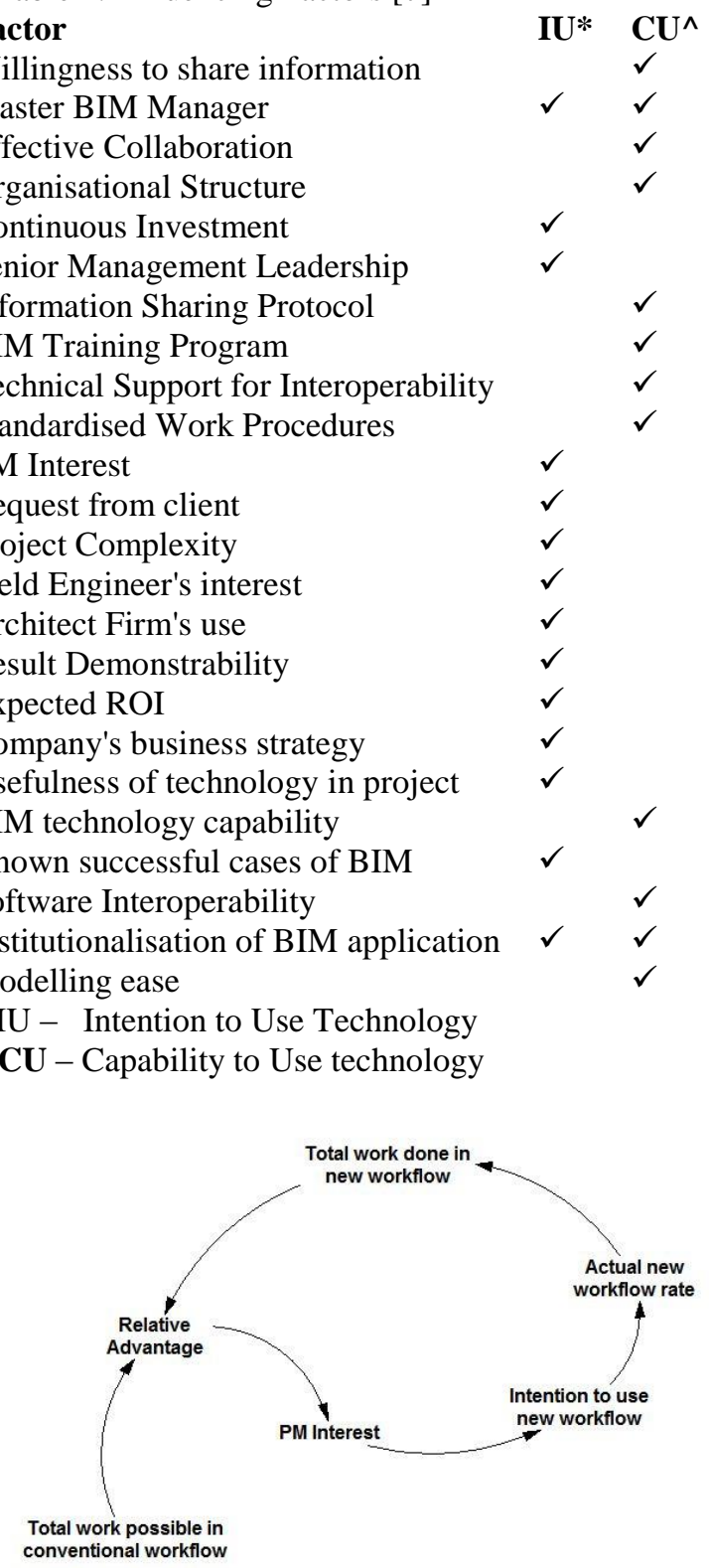

Figure 4. Representation of a CSF being accommodated in abstract model

\section{Discussion on System Dynamics Model}

As there are many available features in system 
dynamics software, the insights that one can get from a SD model are many. Here, only two key benefits are discussed:

1. When the two hypothetical models were combined, the impact of timing of introducing the two modules - 'clash detection' and 'status reporting' could be analysed. This is an indicator that decision makers could use system dynamics models to understand the significance of timing of introducing technology modules.

2. Huge sets of inputs can be programmatically given to the system dynamics model by systematically varying the values of different variables. System dynamics software could use these inputs in generating corresponding set of project outcomes. Project designers can now fine tune their designs based on the required output, unchangeable inputs and changeable inputs.

\section{Summary}

A reusable system dynamics based framework (Figure 3) that can be used for modelling technology adoption process in construction industry has been proposed based on literature review and field study. The paper has demonstrated the feasibility of utilising system dynamics based approach to develop a model of technology adoption in construction projects.

\section{References}

[1] Basoglu, N., Daim, T. and Kerimoglu, O. Organizational adoption of enterprise resource planning systems: A conceptual framework. The Journal of High Technology Management Research, 18(1): p. 73-97, 2007.

[2] Chuttur, M. Overview of the technology acceptance model: Origins, developments and future directions. Online: http://sprouts.aisnet.org/9-37,Accessed: $30 / 05 / 2014$

[3] Bagozzi, R.P. The Legacy of the Technology Acceptance Model and a Proposal for a Paradigm Shift. Journal of the Association for Information Systems, 8(4): p. 3, 2007

[4] Boland, R.J., Lyytinen,K. and Yoo,Y. Wakes of innovation in project networks: The case of digital 3-D representations in architecture, engineering, and construction. Organization Science, 18(4): p. 631-647,2007.

Dossick, C.S. and Neff, G. Messy talk and clean technology: communication, problemsolving and collaboration using Building Information Modelling. The Engineering Project Organization Journal, 1(2): p. 83-93, 2011.

[6] Whyte, J. Managing digital coordination of design: emerging hybrid practices in an institutionalized project setting. Engineering Project Organization Journal, 1(3): p. 159-168, 2011.

[7] Won, J., Lee, G., Dossick, G. Where to Focus for Successful Adoption of BIM within an Organization. Journal of Construction Engineering and Management. 139(11), 2013.

Sushil. System Dynamics : A practical approach for Mangerial Problems. Wiley Eastern Publication, New Delhi. 1993.

[9] Sterman, J.D., System dynamics modeling for project management. Online: http://jsterman.scripts.mit.edu/ jsterman/docs/ Sterman-1992-SystemDynamicsModeling.pdf. 01/04/2013, Accessed: 30/05/2014

[10] Fisher, D.K., Norvell, J., Sonka, S. and Nelson M.J. Understanding technology adoption through system dynamics modeling: implications for agribusiness management. The International Food and Agribusiness Management Review. 3(3): p. 281-296, 2000.

[11] Venkatesh, V., Morris M. G., Davis G. B., and Davis F.D. User acceptance of information technology: Toward a unified view. MIS Quarterly. 27(3), 2003.

[12] Thompson, R.L. and Higgins, C.A. Personal Computing: Toward a Conceptual Model of Utilization. MIS quarterly. 15(1),1991.

[13] Fishbein, M. and Ajzen, I. Belief, attitude, intention and behavior: An introduction to theory and research. Reading, Mass: AddisonWesley Pub. Co.1975.

[14] Venkatesh, V. and Davis, F.D. A theoretical extension of the technology acceptance model: 
four longitudinal field studies. Management Science. 46(2): p. 186-204, 2000.

[15] Vallerand, R.J. Toward a hierarchical model of intrinsic and extrinsic motivation.Advances in Experimental Social Psychology. 29: p 271 360, 1997.

[16] Marks, D.F. The health psychology reader. Sage Publications.2002.

[17] Rogers, E.M. Diffusion of Innovations. 5 ed. 2 Free Press. 2003.

[18] Hartmann, T., Meerveld, H., Vossebeld, N. and Adriaanse A. Aligning building information model tools and construction management methods. Automation in Construction. 22.p 605-613, 2012.

[19] Soffer, P., Golany, B. and Dori, D. Aligning an ERP system with enterprise requirements: An object-process based approach. Computers in Industry. 56(6): p. 639-662, 2005.

[20] Giddens, A. The constitution of society: Outline of the theory of structuration. Univ of California Press.1984.

[21] DeSanctis, G. and Poole, M.S. Capturing the complexity in advanced technology use: Adaptive structuration theory. Organization Science. 5(2): p. 121-147,1994

[22] Orlikowski, W.J. The duality of technology: Rethinking the concept of technology in organizations. Organization Science. 3(3): p. 398-427, 1992.

[23] Kellogg, K.C., Orlikowski, W.J. and Yates, J.A. Life in the trading zone: Structuring coordination across boundaries in postbureaucratic organizations. Organization Science. 17(1): p. 22-44, 2006.

[24] Sargent, K., Hyland, P. and Sawang, S. Factors influencing the adoption of information technology in a construction business. Australasian Journal of Construction Economics and Building. 12(2): p. 86,2012.

[25] Peansupap, V. and Walker, D. Exploratory factors influencing information and communication technology diffusion and adoption within Australian construction organizations: a micro analysis. Construction Innovation: Information, Process, Management. 5(3): p. 135-157, 2005

[26] Nikas, A., Poulymenakou, A., and Kriaris, P. Investigating antecedents and drivers affecting the adoption of collaboration technologies in the construction industry. Automation in Construction. 16(5): p. 632-641, 2007.

Baxter, G. and Sommerville, I. Socio-technical systems: From design methods to systems engineering. Interacting with Computers. 23(1) p. $4-17,2011$

[28] Kadefors, A. Institutions in building projects: implications for flexibility and change. Scandinavian Journal of Management. 11(4): p 395-408. 1995

[29] Engwall, M. No project is an island: linking projects to history and context. Research Policy. 32(5): p. 789-808, 2003. 